\title{
An Index-based Method to Manage the Tradeoff between Diversity and Commonality during Product Family Design
}

\author{
Henri J. Thevenot, ${ }^{1}$ Fabrice Alizon, ${ }^{2}$ Timothy W. Simpson ${ }^{1, *}$ and Steven B. Shooter ${ }^{2}$ \\ ${ }^{1}$ The Harold \& Inge Marcus Department of Industrial \& Manufacturing Engineering \\ The Pennsylvania State University, University Park, PA 16802, USA \\ ${ }^{2}$ Department of Mechanical Engineering, Bucknell University, Lewisburg, PA 17837, USA
}

\begin{abstract}
The competitiveness in today's market forces many companies to rethink the way they design products. Instead of developing one product at a time, many manufacturing companies are developing families of products to provide enough variety for the marketplace while keeping costs relatively low. Although the benefits of commonality are widely known, many companies are still not taking full advantage of it when developing new products or redesigning existing ones. One reason is the lack of appropriate methods and useful indices to assess a product family based on commonality and diversity. Although many component-based commonality indices have been proposed in the literature, they emphasize commonality at the expense of diversity in a product family. In this study, the design for commonality and diversity method based on two new commonality indices - the commonality diversity index and the comprehensive metric for commonality - is introduced to help designers manage the inherent tradeoff between commonality and diversity during the product family design process. To illustrate the proposed method, an example application involving a family of single-use cameras is presented. The proposed method provides useful recommendations at both the functional and component levels during product family design.
\end{abstract}

Key Words: commonality index, diversity, variety, product family design.

\section{Introduction}

In today's increasingly competitive market, many companies need to satisfy a wide range of customer needs while keeping manufacturing costs as low as possible, and thus they are faced with the challenge of providing as much variety as possible for the market with as little variety as possible between the products. Instead of designing new products one at a time, which results in poor commonality and standardization and increases costs, many companies are now designing families of products based on common 'elements' embodied in a product platform, enabling cost-effective development of a sufficient variety of products to meet customers' diverse demands.

There are many cost-savings advantages of implementing platform commonality while developing a new family of products: decreased lead-time and risk in the development stage [1-3], reduction of inventory and handling costs, reduction of product line complexity, setup and retooling time, increased standardization $[1,2,4]$, and fewer components to test and qualify within the family $[5,6]$. Too much

*Author to whom correspondence should be addressed. E-mail: tws8@psu.edu Figure 1, Appendix A and B appear in color online: http://cer.sagepub.com commonality (i.e., not enough diversity) within a product family can also have major drawbacks, including lack of product distinctiveness (i.e., mass confusion) [7], lack of innovation and creativity, and compromised product performance [8]. Consequently, there is a tradeoff between commonality and diversity within any product family [9]. The optimal level of commonality is obtained by minimizing the non-value added variations across the products within a family without limiting the choices for customers in each market segment. From a more general view, the idea is to make each product within a family distinctive in ways that customers notice and is identical in ways that customers cannot see [10].

In this study, the design for commonality and diversity method (DCDM) is introduced to help designers manage the inherent tradeoff between commonality and diversity during all stages of the product family design process. The proposed method is based on two new commonality indices: the commonality diversity index (CDI, [11]) and the comprehensive metric for commonality (CMC, [12]). Unlike the other componentbased commonality indices, the CDI and the CMC provide useful information at the functional and component levels to help designers manage the tradeoff between commonality and variety in a product family.

The study is articulated as follows. In Section 2, a literature review covering existing metrics for product 
family design as well as their limitations is described. The CDI and the CMC are then described and compared to other component-based commonality indices. In Section 3, existing product family design approaches are reviewed as well as their limitations. The DCDM is then introduced and applied to an example application in Section 4. Finally, Section 5 gives closing remarks and future work.

\section{Indices for Assessing Commonality and Variety in a Product Family}

\subsection{Existing Metrics for Product Family Design}

An important measure of the success of a product platform is how quickly and cheaply new products can be developed from it [13]. There are two common approaches for product family design and redesign: modularity and commonality. Modularity arises from the decomposition of a product family into unique and common modules. Several studies regarding the measure of product modularity and methods to achieve modularity in product redesign can be found in the literature: Gershenson et al. [14] provide a recent overview of modularity and its benefits as well as a comparison of existing measures of product modularity [15].

To assess the degree of commonality within a product family, several commonality indices have been developed based on different parameters, such as the number of common components, their connections, their costs, etc. This includes the degree of commonality index (DCI, [2]), the total constant commonality index (TCCI, [16]), the commonality index (CI, [17]), the component part commonality index $\left(\mathrm{CI}^{(\mathrm{C})},[18]\right)$, the product line commonality index (PCI, $[19])$, the percent commonality (\%C, [20]), the generational variety index (GVI, [21]), the functional similarity index (FSI, [22,23]), and measures for the degree of variation $[9,24,25]$. An extensive comparison between many of these commonality indices and their usefulness for product family design (and redesign) can be found in [10], and a comprehensive list of existing commonality indices can be found in $[26,27]$.

\subsection{Limitations of the Existing Commonality Indices}

While the aforementioned indices may help designers manage the tradeoff between too much commonality (lack of product performance and product differentiation) and not enough commonality (higher manufacturing costs), they are not helpful in evaluating the impact of each component on the degree of commonality within the family. For example, the CI, TCCI, and DCI only consider the components in each product and compare them to see if they are common, variant, and/or unique. They do not consider component costs, production volume, materials, manufacturing processes, and assembly, which is important information for ascertaining the cost-savings benefits of commonality within a product family. Meanwhile, the $\mathrm{CI}^{(\mathrm{C})}$ takes costs into account, but it does not account for differences in material, manufacturing processes, or assembly. In other words, these indices can only reach their 'perfect' value for commonality when all the parameters are common between all the components in all the products in the family, regardless of whether these components are adding variety to the family or not. As such, the previously described indices do not assess the diversity in a product family: only the PCI allows for unique components, while the other indices promote commonality among all components, including the ones that should remain unique or variant to differentiate products in the family. Consequently, there is a need for indices that assess the effect of each component on the overall level of commonality and diversity in the product family. The CDI and the CMC presented next integrate various aspects of the aforementioned indices to capture more information for each component and function to assess the impact of each component on the overall level of commonality and diversity in a product family.

\subsection{The Commonality Diversity Index}

The CDI scores the difference between existing and ideal tradeoff within and across a family of products with different depth of analysis (function, component, and family levels) [11]. The ideal tradeoff is defined as follows: (1) common functionality should use common components, (2) unique functions should use unique components, and (3) variant functions should use variant components, in the same proportion. Functions are defined by function attributes, which help identify the 'ideal' common, variant, and unique components based on the values that each function attribute takes for each product. For example, for the function 'Store Image', one corresponding function attribute is the 'Sensitivity' and can take the values ISO100, ISO200, ISO400, etc.). If a component is used by several functions, the choice is made to score the component for all these functions. This index is computed for an existing family of products and can also be used at the functional level of abstraction during the early stages of product family design to help determine the ideal tradeoff. The CDI ranges from 0 to 1 , where 1 indicates a perfect balance between the commonality and diversity and 0 indicates a failure to do so. 
Let $P=\left(P_{1}, \ldots, P_{N}\right)$ be a family of $N$ products that has $F$ functions $f_{i}(i=1-F)$. Let $f_{i}$ be a given function in the product family where $f_{i}$ is achieved by a set of components. Denote $c_{i k}(k=1-K)$ the components for this function $f_{i}$. Given $k, c_{i k}$ refers to the generic component. The physical representations or instances of this generic component in the products $P_{1} \ldots P_{N}$ are denoted $c_{i k}^{j}$, for $j=1 \ldots N\left(c_{i k}^{j}=\right.$ null if the component $c_{i k}$ has no instance in product $j$ ). For each generic component $c_{i k}$ of the function $i$, sub-groups of the product family are defined, which correspond to the number of platforms within the family. Thus, for each component $c_{i k}$ there are $G_{i k}$ sub-groups: $g_{m}$, $l=1 \ldots G_{i k}$. In each sub-group $g_{m}$, there is commonality and diversity specified by marketing such that the final design meets or does not meet these specifications. Hence, the authors speak of allowed diversity and nonallowed commonality-diversity that is specified for components. The 'non-allowed commonality' corresponds to specific components that should not be common, and 'non-allowed diversity' refers to common components that should not be specific. Let $c_{i k}^{j}$ be the ideal instance and $c_{i k}^{\prime j}$ be the actual instance of component $k$ in product $j$. For common components, the indicator function is defined:

$$
\mathbb{1}\left\{c_{i k}^{j} \neq c_{i k}^{\prime j}\right\}=1 \quad \text { if } c_{i k}^{j} \neq c_{i k}^{\prime j} \text { and } 0 \text { otherwise. }
$$

In the same way, for specific components the indicator function is defined:

$$
\mathbb{1}\left\{c_{i k}^{j}=c_{i k}^{\prime j}\right\}=1 \quad \text { if } c_{i k}^{j}=c_{i k}^{\prime j} \text { and } 0 \text { otherwise. }
$$

Thus, the non_allowed_com_div of a given sub-group is equal to the sum of both indicator functions for all the components in the sub-group:

$$
\begin{aligned}
\text { non_allowed_com_div }{ }_{i k g_{m}}= & \sum_{P_{j \in P \cap g_{m}}} 11 c_{i k}^{j j}\left\{c_{i k}^{j} \neq c_{i k}^{\prime j}\right\} \\
& +\sum_{P_{j \in P \cap g_{m}}} 1 c_{i k}^{j}\left\{c_{i k}^{j}=c_{i k}^{\prime j}\right\}
\end{aligned}
$$

where in the first sum, only common components are taken into account, and in the second sum, only specific components are considered. Averaging the CDI score for all the sub-groups $g_{m}$ of the generic component $c_{i k}$ is then:

$\mathrm{CDI}_{\text {Component } k}=\frac{1}{G_{i k}} \sum_{m=1}^{G_{i k}}\left(1-\frac{\text { non_allowed_com_div }_{i k g_{m}}}{\max \operatorname{div}_{i k g_{m}}}\right)$.
This score on the set of generic components is the average score of the function $f_{i}$ :

$$
\begin{aligned}
& \text { CDI }_{\text {Function } i} \\
& =\frac{1}{K_{i j}} \sum_{k=1}^{K_{i j}} \frac{1}{G_{i k}} \sum_{m=1}^{G_{i k}}\left(1-\frac{\text { non_allowed_com_div }_{i k g_{m}}}{\max \operatorname{div}_{i k g_{m}}}\right) .
\end{aligned}
$$

Then the overall score for the family of products $\mathrm{P}$ is:

$$
\begin{aligned}
\mathrm{CDI}_{\text {Family } P}= & \frac{1}{F} \sum_{i=1}^{F} \frac{1}{K_{i j}} \sum_{k=1}^{K_{i j}} \frac{1}{G_{i k}} \\
& \times \sum_{m=1}^{G_{i k}}\left(1-\frac{\text { non_allowed_com_div }_{i k g_{m}}}{\max , \operatorname{div}_{i k g_{m}}}\right) .
\end{aligned}
$$

More details are found in [11]. One of the strengths of the CDI is its ability to analyze the commonality and diversity with variable depth of analysis by computing the $\mathrm{CDI}_{\text {component }}$, the $\mathrm{CDI}_{\text {function, and the }} \mathrm{CDI}_{\text {family }}$ within and across families.

\subsection{The Comprehensive Metric for Commonality}

The CMC is a component-based commonality metric that uses the following information to assess commonality [12]: size and geometry, manufacturing process, material, assembly/fastening scheme, production volume, and initial cost (e.g., cost of producing a mold for an injection plastic process).

The CMC is defined as:

$$
\mathrm{CMC}=\frac{\sum_{i=1}^{N} n_{i} *\left(C_{i}^{\max }-C_{i}\right) * \prod_{x=1}^{4} f_{x i}}{\sum_{i=1}^{N} n_{i} *\left(C_{i}^{\max }-C_{i}^{\min }\right) * \prod_{x=1}^{4} f_{x i}^{\max }}
$$

where $N$ is the total number of components; $n_{i}$ is the number of products in the product family that have component $i ;\left\{f_{1 i}, f_{2 i}, f_{3 i}, f_{4 i}\right\}$ is the ratio of the greatest number of products that share component $i$ with identical ssize and shape $\left(f_{1 i}\right)$, materials $\left(f_{2 i}\right)$, manufacturing processes $\left(f_{3 i}\right)$, assembly and fastening schemes $\left.\left(f_{4 i}\right)\right\}$ to the number of products that have component $i\left(n_{i}\right) ;\left\{f_{1 i}^{\max }, f_{2 i}^{\max }, f_{3 i}^{\max }, f_{4 i}^{\max }\right\}$ is the ratio of the greatest number of products that share component $i$ with identical ssize and shape $\left(f_{1 i}^{\max }\right)$, materials $\left(f_{2 i}^{\max }\right)$, manufacturing processes $\left(f_{3 i}^{\max }\right)$, assembly and fastening schemes $\left.\left(f_{4 i}^{\max }\right)\right\}$ to the greatest possible products that could have shared component $i$ with identical size and shape schemes; $C_{i}$ is the current total cost for component $i=\sum_{j=1}^{n_{i}} C_{i j} ; C_{i j}$ is the total cost for component $i$ variant $j=Q_{i j} * c_{i j}$; $Q_{i j}$ is the quantity of component $i$ variant $j$; $c_{i j}$ is the unit cost for component $i$ variant $j ; C_{i}^{\min }$ is the minimum total cost for 
Table 1. Comparison of the commonality indices based on the information used.

\begin{tabular}{|c|c|c|c|c|c|c|c|c|c|}
\hline $\begin{array}{l}\text { Commonality } \\
\text { Indices }\end{array}$ & $\begin{array}{l}\text { Functions } \\
\text { in } \\
\text { product }\end{array}$ & $\begin{array}{l}\text { Can be used in } \\
\text { the early } \\
\text { stages } \\
\text { of a project }\end{array}$ & $\begin{array}{c}\text { Penalizing } \\
\text { commonality } \\
\text { and variety only } \\
\text { when not desired }\end{array}$ & $\begin{array}{c}\text { Value } \\
\text { Variety } \\
\text { when needed }\end{array}$ & $\begin{array}{l}\text { Multi- } \\
\text { Platform }\end{array}$ & Bounded & $\begin{array}{l}\text { Size, geometry, } \\
\text { materials, } \\
\text { manufacturing } \\
\text { processes }\end{array}$ & $\begin{array}{l}\text { Assembly } \\
\text { schemes }\end{array}$ & $\begin{array}{l}\text { Component } \\
\text { costs }\end{array}$ \\
\hline $\mathrm{DCl}$ & No & No & No & No & No & No & No & No & No \\
\hline $\mathrm{TCCl}$ & No & No & No & No & No & Yes & No & No & No \\
\hline $\mathrm{Cl}$ & No & No & No & No & No & Yes & No & No & No \\
\hline $\mathrm{PCl}$ & No & No & No & No & No & Yes & Yes & Yes & No \\
\hline$\% \mathrm{C}$ & No & No & No & No & No & Yes & No & Yes & No \\
\hline $\mathrm{Cl}^{(\mathrm{C})}$ & No & No & No & No & No & No & No & No & Yes \\
\hline CDI & Yes & Yes & Yes & Yes & Yes & Yes & No & No & No \\
\hline $\mathrm{CMC}$ & No & No & Yes & No & Yes & Yes & Yes & Yes & Yes \\
\hline
\end{tabular}

component $i=\sum_{j=1}^{n_{i}} C_{i j}^{\min } ; C_{i}^{\max }=$ maximum total cost component $=\sum_{j=1}^{n_{i}} C_{i j}^{\max }$ (computed by taking the most expensive variant available and the most expensive materials).

$C_{i}^{\min }$ is obtained when the 'perfect' balance of commonality and variety is obtained for component $i$, i.e., when all the non-differentiating instances of component $i$ are common across the products, while the differentiating instances of component $i$ are maintained variant. $C_{i}^{\max }$ is obtained when the 'worst' balance of commonality and variety is present for component $i$, i.e., when all the instances are different between all the products in the family, each instance being produced without any commonality. The choice of the cost estimate is independent of the CMC formulation. For this study, a simple cost model is used (see [12]).

The CMC weights the components in the products based on their costs as well as their size and geometry, material, manufacturing process, and assembly process. The $\mathrm{CMC}$ ranges from 0 to 1 . The $\mathrm{CMC}$ equals 1 when all the non-differentiating components are common between all the products in the family, and they use the cheapest variant available (a non-differentiating component is not used to differentiate the products, neither aesthetically or functionally), and the $\mathrm{CMC}$ is equal to 0 when all the components are different (size, geometry, manufacturing process, assembly, material) between all the products.

\subsection{Comparison of the Commonality Indices}

Table 1 compares six existing component-based commonality indices with the CDI and CMC. The following points can be observed based on Table 1 .

(1) Only the CDI can be used in the early stages of a project when only functional requirements are available; the other indices require componentbased data to be computed. The CDI helps identify the ideal functional tradeoff (what should or should not be common), which designers can then use to specify components.
(2) The CDI and the CMC are the only two indices that penalize only commonality and variety when they are not desired. By doing so, the maximum value (in this case, 1) can potentially be obtained when all the non-differentiating components are common, while in the other indices, the maximum value is obtained when all the components are common between all the products in a product family, including the differentiating components (except for the PCI, which does not consider unique components.

(3) The CDI is the only index that rewards variety when it is desired, helping to identify functions that lack variety.

(4) The CDI looks even more explicitly at the diversity issue than the $\mathrm{CMC}$ by grouping the components into functions, hence making it easy for designers to identify the components and/or the functions that lack variety.

(5) The CMC assesses each component of a product family more comprehensively. The component costs are related to the production volume, the material used, the component volume, and the initial costs. The different variants in geometry, in material, and in manufacturing processes of each component are analyzed as well.

(6) Finally, the CDI and the CMC are the only two indices that can manage a product family based on several platforms (see [11] for more detail).

By combining the use of the CDI and the CMC, the appropriate balance of commonality and variety in a product family can be identified and managed. While the CDI focuses more explicitly on variety, the CMC focuses more on component costs. Hence, by only looking at the CDI, designers cannot directly identify which components are the most expensive to produce and penalize the family, but can rather look at which components do not respect the desired variety. On the other hand, the CMC does not focus on the components that need to provide variety, but rather on the impact of each component on the commonality and variety in a product family. For example, by only looking at 
the CDI, designers might overlook components that are expensive to produce, yet by looking only at the CMC, designers might overlook components that are required to produce enough variety to meet customers' needs. Hence, it is asserted that the combined use of the CDI and the CMC as discussed next provides a more thorough assessment of a product family compared to the other existing component-based commonality indices.

\section{Product Family Design and the Design for Commonality and Diversity Method}

\subsection{Product Family Design Approaches}

There are two recognized approaches to product family design [28]: top-down and bottom-up. In a topdown (proactive platform) approach, the company's strategy is to develop a family of products based on a product platform and its derivatives. Top-down approaches found in the literature include the product platform concept exploration method [28], the variationbased platform design methodology [25], the design for variety method [21] and the key metrics-based approach [29]. In a bottom-up (reactive redesign) approach, a company redesigns and/or consolidates a group of distinct products to standardize components and thus reduce costs. Bottom-up approaches found in the literature include product family redesign at John Deere [30] and Sunbeam [31], a method to redesign a large product set to improve product performance and reduce manufacturing costs [30], the redesign of an existing line of products using consumers' evaluations of possible new design with a marketing research technique (conjoint analysis) [31], the product family reasoning system [32], and an optimization-based redesign approach based on commonality analysis [33]. Additional optimization-based approaches are reviewed in [27].

\subsection{Limitations of the Existing Approaches for Product Family Design}

First, most of the existing approaches cannot be used during the various stages of the product family design process, as they need detailed information on the products in the product family to design/redesign. Second, they do not explicitly address the issue of variety and commonality in a product family. They focus on maximizing the commonality in a family, but overlook the desired variety for the end-user. The DCDM introduced next addresses these issues and helps designers manage the tradeoff between commonality and diversity during all stages of the product family design process.

\subsection{The Design for Commonality and Diversity Method}

The proposed DCDM uses the CDI and the CMC to help designers during all the stages of the product family design process. It is assumed in this method that the cost is minimized when the non-differentiating components are as common as possible between the products while keeping differentiating components variant. This is a strong assumption that do not always hold true (e.g., when variable costs are high, see [6,34]), and the proposed method does not work in this case. Figure 1 shows the product realization process divided in two stages: (1) preliminary project (definition of customers' needs and functional requirements, as well as preliminary product and process design) and (2) detailed studies (detailed product and process design). The DCDM works in both stages, as shown in Figure 1:

- in Stage 1 (preliminary project), the DCDM uses the CDI to help designers focus on which functions to make common, variant or unique in the product family; and

- in Stage 2 (detailed studies), the DCDM uses both CDI and CMC to (1) to ensure that the functions and the corresponding components still possess the appropriate diversity and commonality and (2) help designers improve the commonality between components without sacrificing diversity in the product family. The DCDM is described in detail next. An example implementation follows in Section 4.

\subsubsection{STAGE 1: PRELIMINARY PROJECT}

In Stage 1, designers working along with the marketing team define the extent of the product line, the desired diversity provided by the different products, as well as the desired commonality between products at the functional level. This is not the focus of this study; extensive literature can be found on how to link customer needs and functional requirements, such as the methods proposed in [35]. The CDI is used in this stage to support existing tools by focusing on which function(s) should be kept variant/unique and which function(s) should be made common between products. For instance, when a function is invisible to customers or does not affect their evaluation of product performance, designers may prefer to achieve higher commonality for this function. On the other hand, the differentiating functions should remain unique to each product. Stage 1 operates as follows:

- List all functions in all the products to be designed (using appropriate tools along with customers' needs and functional requirements). 


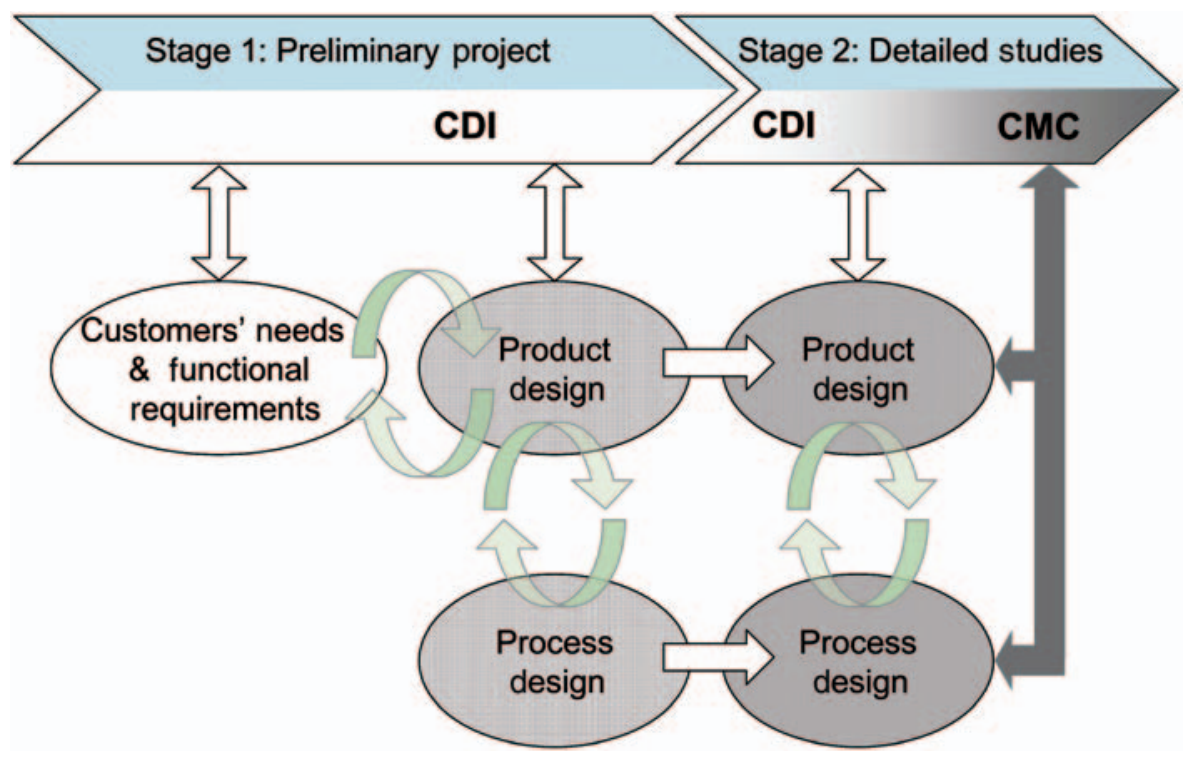

Figure 1. Product design process and the DCDM.

- Define the functions as either being common (shared between all the products having this function), variant (variant of a function in the products, due for example to different levels of performance for the function), or unique (function only in one product). The corresponding CDI value is 1 .

- Generate concepts for each function and compute the CDI for the alternative concepts.

- Select the concept(s) with the highest CDI value for each function.

The computation of the CDI for different concepts allows designers to compare the level of commonality/ diversity in a specific concept with the theoretical commonality/diversity defined previously. For example, let it be assumed that a function is defined as being variant between all the products in a family (i.e., the function is common to all products but its attributes are different for each). Designers find two concepts that can achieve this function. If the first concept generated for this function has common attributes between all the products, then the diversity is not respected, penalizing the CDI value. On the other hand, if the second concept varies in the same proportion as what is required in the function, then the concept is not penalized in the CDI, and designers will consider the second concept as a better alternative.

\subsubsection{STAGE 2: DETAILED STUDIES}

By using the CDI in Stage 1, designers select the best concept (platform and variant functions and components) while keeping in mind the degree of variety and commonality that each function should provide. In Stage 2, the products and their components are defined, and the DCDM now uses both CDI and $\mathrm{CMC}$ to (1) ensure that the definition of the components still respect the desired variety and commonality and (2) improve the design of the family. The CDI is now used to ensure that the tradeoff between commonality and diversity is not lost when the design of each product is refined, while the CMC is employed to assess more comprehensively the design and improve it. By integrating information, such as the manufacturing processes, materials, assembly, and component costs, the CMC employed with appropriate optimization tools $[33,36]$ provides recommendations for designers on where and how to increase commonality without losing the desired variety.

Stage 2 operates as follows:

- Use the CMC to assess the design of the product family; if several competing designs exist, the CMC helps designers select the best one (see $[33,36]$ for more detail).

- Improve the selected design using the CMC and appropriate optimization tools $[33,36]$ to increase commonality (component, material, manufacturing process, assembly) while keeping the desired variety.

- Use the CDI to ensure that the design possesses the desired commonality and variety at the functional, component, and family levels throughout Stage 2.

In the next section, an example application is given to illustrate the use of the DCDM for a family of single-use cameras.

\section{Example Application}

To demonstrate the proposed method, an example application consisting of a set of six single-use cameras (see Table 2) is analyzed using the DCDM during 
Table 2. Family of single-use cameras analyzed.

\begin{tabular}{lllll}
\hline Funsaver & Power flash & Plus digital & High definition & Black and white \\
\hline & &
\end{tabular}

Table 3. List of functions for the six cameras.

\begin{tabular}{ll}
\hline Function & Type \\
\hline Display information & Common \\
Condition the image & Variant \\
Protect against the environment & Variant \\
View the scene & Common \\
Light the scene & Variant \\
Control the exposure time & Common \\
Store images & Variant \\
Advance film & Variant \\
\hline
\end{tabular}

Stage 1 (see Section 4.1) and Stage 2 (see Section 4.2). While this set of cameras already exists, this example is used for illustrative purposes, and hence it is assumed that the design of the products is not know a priori and that the design will be refined during Stage 2.

\subsection{Stage 1: Preliminary Project}

In Stage 1, customers' needs are used to define the functional requirements. For this example, eight functions are identified for the cameras, listed in Table 3.

The functions are then classified as either common, variant, or unique between the cameras (see Table 3), and for each function, a separate table is created to show the ideal commonality and diversity. For example, in Table 4, the function 'View Scene' is desired to be common between all the products. In Table 5, the function 'Store Image' is defined as variant, due to different levels for this functional requirement: four cameras can potentially share the same concept for the function 'Store Image,' but two cameras need a variant solution (the black and white and the high definition cameras).

Once the functions have been identified and classified, designers start generating concepts using appropriate concept generation and selection methods while keeping in mind the desired commonality and variety that each function should provide. The concepts generated should be chosen for each product in the product family. Looking at the function 'Store Image', designers may come up with two concepts: regular film or a digital sensor coupled with memory. Both concepts may be
Table 4. Example of common function and the corresponding CDI.

\begin{tabular}{lcc}
\hline Function & Camera & Diversity \\
\hline \multirow{3}{*}{ View the scene } & Plus digital & 1 \\
& High definition & 1 \\
& Water and sport & 1 \\
& Power flash & 1 \\
& Black and white & 1 \\
Score & Funsaver & 1 \\
\hline
\end{tabular}

Table 5. Example of variant function and the corresponding CDI.

\begin{tabular}{lcc}
\hline Function & Camera & Diversity \\
\hline \multirow{3}{*}{ Store images } & Plus digital & 1 \\
& High definition & 2 \\
& Water and sport & 1 \\
& Power flash & 1 \\
& Black and white & 3 \\
Score & Funsaver & 1 \\
\hline
\end{tabular}

leveraged to offer the desired variety, but other constraints (such as manufacturing costs) eliminate the second concept. Therefore, the concept 'film' is chosen for the function 'Store Image.' The next step is to refine the concept 'film' to come up with physical solutions for each product. Consider the four detailed concepts listed in Table 6. In detailed concept 1 , a common $35 \mathrm{~mm}$ color film is shared between all the cameras. The CDI is computed for each alternative. By doing so, the concept that achieves the highest CDI value is selected for Stage 2. In this example, detailed concepts 1 and 3 do not provide the desired variety $(\mathrm{CDI}<1)$ : a different technical solution is desired for two cameras (the high definition and the black and white). Detailed concepts 2 and 4 achieve the highest CDI value (1); in this case, other parameters, such as manufacturing costs, etc. are used to help choose the 'best' concept between those two. In this case, it is assumed that the $24 \mathrm{~mm}$ film is more expensive than a $35 \mathrm{~mm}$ film (due to the production volume); hence, detailed concept 2 is selected to enter Stage 2. The CDI helps designers determine 
Table 6. Examples of concepts generated for the function 'Store Image.'

\begin{tabular}{|c|c|c|c|c|c|c|c|}
\hline & Funsaver & Power flash & Plus digital & High definition & $\begin{array}{l}\text { Black and } \\
\text { white }\end{array}$ & $\begin{array}{l}\text { Water and } \\
\text { sport }\end{array}$ & $\begin{array}{l}\text { CDI for } \\
\text { 'Store } \\
\text { Image' }\end{array}$ \\
\hline Ideal & Technical & Technical & Technical & Technical & Technical & Technical & 1 \\
\hline Concept & Solution 1 & Solution 1 & Solution 1 & Solution 2 & Solution 3 & Solution 1 & \\
\hline $\begin{array}{l}\text { Detailed } \\
\text { Concept } 1\end{array}$ & $\begin{array}{l}35 \mathrm{~mm} \text { film } \\
\text { color }\end{array}$ & $\begin{array}{l}35 \mathrm{~mm} \text { film } \\
\text { color }\end{array}$ & $\begin{array}{l}35 \mathrm{~mm} \text { film } \\
\text { color }\end{array}$ & $\begin{array}{l}35 \mathrm{~mm} \text { film } \\
\text { color }\end{array}$ & $\begin{array}{l}35 \mathrm{~mm} \text { film } \\
\text { color }\end{array}$ & $\begin{array}{l}35 \mathrm{~mm} \text { film } \\
\text { color }\end{array}$ & 0.75 \\
\hline $\begin{array}{l}\text { Detailed } \\
\text { Concept } 2\end{array}$ & $\begin{array}{l}35 \mathrm{~mm} \text { film } \\
\text { color }\end{array}$ & $\begin{array}{l}35 \mathrm{~mm} \text { film } \\
\text { color }\end{array}$ & $\begin{array}{l}35 \mathrm{~mm} \text { film } \\
\text { color }\end{array}$ & $\begin{array}{l}35 \mathrm{~mm} \text { film } \\
\text { high quality }\end{array}$ & $\begin{array}{c}35 \mathrm{~mm} \text { film } \\
\text { black and white }\end{array}$ & $\begin{array}{l}35 \mathrm{~mm} \text { film } \\
\text { color }\end{array}$ & 1 \\
\hline $\begin{array}{l}\text { Detailed } \\
\text { Concept } 3\end{array}$ & $\begin{array}{l}35 \mathrm{~mm} \text { film } \\
\text { color }\end{array}$ & $\begin{array}{l}24 \text { mm film } \\
\text { color }\end{array}$ & $\begin{array}{l}24 \text { mm film } \\
\text { color }\end{array}$ & $\begin{array}{l}24 \mathrm{~mm} \text { film } \\
\text { high quality }\end{array}$ & $\begin{array}{c}24 \mathrm{~mm} \text { film } \\
\text { black and white }\end{array}$ & $\begin{array}{l}35 \mathrm{~mm} \text { film } \\
\text { color }\end{array}$ & 0.90 \\
\hline $\begin{array}{l}\text { Detailed } \\
\text { Concept } 4\end{array}$ & $\begin{array}{l}24 \text { mm film } \\
\text { color }\end{array}$ & $\begin{array}{l}24 \text { mm film } \\
\text { color }\end{array}$ & $\begin{array}{l}24 \text { mm film } \\
\text { color }\end{array}$ & $\begin{array}{l}24 \mathrm{~mm} \text { film } \\
\text { high quality }\end{array}$ & $\begin{array}{c}24 \mathrm{~mm} \text { film } \\
\text { black and white }\end{array}$ & $\begin{array}{l}24 \text { mm film } \\
\text { color }\end{array}$ & 1 \\
\hline
\end{tabular}

Table 7. Impact of the components on the overall commonality.

\begin{tabular}{|c|c|c|c|c|c|c|c|c|c|c|c|}
\hline Component & Type & $f 1$ & f2 & f3 & f4 & $n_{\mathrm{i}}$ & $C_{i}$ & $\mathbf{C}_{i}^{\max }$ & $\mathbf{C}_{i}^{\min }$ & $\boldsymbol{n}_{\boldsymbol{i}}\left(\boldsymbol{C}_{\boldsymbol{i}}^{\max }-\boldsymbol{C}_{\boldsymbol{i}}\right) * \prod_{\mathbf{x}=1}^{4} \boldsymbol{f}_{\mathbf{x} \boldsymbol{i}}$ & $\boldsymbol{n}_{\boldsymbol{i}}\left(\boldsymbol{C}_{\boldsymbol{i}}^{\max }-\boldsymbol{C}_{\boldsymbol{i}}^{\min }\right) * \prod_{\mathbf{x}=1}^{4} \boldsymbol{f}_{\mathrm{xi}}^{\max }$ \\
\hline Arm 1 & Common & 1 & 1 & 1 & 1 & 6 & 117,650 & 367,650 & 117,650 & $1,500,000$ & $1,500,000$ \\
\hline $\begin{array}{l}\text { Film advance } \\
\text { wheel }\end{array}$ & $\begin{array}{l}\text { Variant non } \\
\text { differentiating }\end{array}$ & $1 / 3$ & $5 / 6$ & 1 & 1 & 6 & 95,100 & 345,100 & 87,400 & 833,333 & $1,546,200$ \\
\hline Film & $\begin{array}{l}\text { Variant } \\
\text { differentiating }\end{array}$ & $1 / 2$ & 1 & 1 & 1 & 6 & $10,250,000$ & $15,000,000$ & $10,250,000$ & $14,250,000$ & $14,250,000$ \\
\hline $\begin{array}{l}\text { Waterproof } \\
\text { back casing }\end{array}$ & Unique & 1 & 1 & 1 & 1 & 1 & 127,500 & 127,500 & 127,500 & 0 & 0 \\
\hline
\end{tabular}

physical solutions with keeping this desired differentiation in mind.

\subsection{Stage 2: Detailed Studies}

\subsubsection{USE OF CDI AND CMC}

Stage 2 starts with the computation of the CMC for the detailed concept selected at the end of Stage 1; it is used to identify in more detail which parameter(s) of which component(s) should be improved to increase commonality while keeping the desired variety. The CMC is computed at the component level. The computation of the CMC for the existing family can be found in Appendix A. The value obtained is 0.61, meaning that the components can be made more common to reduce the overall costs and increase the $\mathrm{CMC}$ value without loosing the desired variety. Each component influences the final value of the CMC using weights that are related to (1) size and geometry, (2) material, (3) process, (4) fastening schemes, and (5) costs. Four different types of components are identified, each having a different impact on the CMC, as shown in Table 7. The components that are common (hence non-differentiating) between all the products in the family are achieved with the lowest cost possible $\left(C_{i}=C_{i}^{\min }\right)$, as illustrated by Arm 1 in the table. The corresponding $f_{i}$ factors are equal to 1 ; and the ratio between the last two columns is equal to 1, which corresponds to the best commonality achievable. In the second row, the film advance wheel is variant between the products, but this component is non-differentiating, and it could potentially be made common between the products. Hence, the corresponding $f_{i}$ factors do not all reach the highest value possible $\left(f_{1}<1\right)$, and the $\operatorname{cost} C_{i}$ is higher than $C_{i}^{\min }$. This is also reflected by the ratio of the last two columns, which is strictly $<1$. The third row shows an example of a variant differentiating component, namely, the 'film', which is variant between products in the family. This variety is not penalized: the ratio of the last two columns is equal to 1 (this relates back to detailed concept 2, where a $35 \mathrm{~mm}$ film with appropriate variants was chosen for the function 'Store Image'). Finally, the unique components, such as the waterproof back casing, does not influence the CMC. By looking at the ratio of the last two columns, the CMC helps designers focus on the components that do not respect the desired diversity and commonality $[12,33]$. Moreover, the CMC can be used in an appropriate optimization-based approach to provide specific information on how to increase the commonality at the component level. For example, the film advance wheel penalizes the desired commonality, and the CMC helps point out how this component should be redesigned. The intent of this study is not to detail this algorithm; the reader may refer to [33] for the implementation of such an algorithm.

Throughout Stage 2, the CDI is also computed; the computation for the current design is detailed in Appendix B. The value obtained for the CDI is higher than that for the CMC: 0.78 versus 0.61 for the CMC. 
Table 8. Computation of the CDI for the function Display Information.

\begin{tabular}{|c|c|c|c|c|}
\hline Function & Camera/Components & Exposure Counter & Viewfinder & Flash Cover \\
\hline & Diversity for the function & $0 \%$ & $0 \%$ & $17 \%$ \\
\hline \multirow[t]{6}{*}{ Display information } & Plus digital & 1 & 1 & 2 \\
\hline & High definition & 2 & 2 & 1 \\
\hline & Water and sport & 1 & 3 & - \\
\hline & Power flash & 3 & 2 & 1 \\
\hline & Black and white & 1 & 1 & 2 \\
\hline & Funsaver & 3 & 4 & 3 \\
\hline Score & 0.50 & 0.60 & 0.40 & 0.50 \\
\hline
\end{tabular}

The reason is that the CDI focuses on the commonality and penalizes variety if it is not provided, without 'weighting' the components using factors, such as costs, etc. What can be concluded from the CDI is that the current design of the family achieves a good diversity, but the ideal value (1) is not reached; hence, there is room for improvement, and the current design does not respect completely the desired variety and commonality in the family. The CDI points out which function(s) and component(s) to improve. For example, for the function 'display information' (see Table 8), three components are used: the 'exposure counter,' the 'viewfinder,' and the 'flash cover'. These three components are nondifferentiating components.

The score at the bottom of each column shows that these three components are not completely common between the six products; hence, the value is $<1$. The score on the left side $(0.53)$ is the average for all three components. As a result, the score is 0.53 for the specific function 'display information', indicating that there is room for improvement in the components used to achieve this function. The CDI value for each function is computed the same way, as shown in Table 9. By looking at these values, designers can easily identify which function to improve: while the functions 'protect against the environment' and 'light the scene' reach a perfect value of 1 , the other functions possess a lower CDI value, meaning that the tradeoff between commonality and variety was not completely respected when developing this design.

The DCDM applied on this example application shows how the $\mathrm{CDI}$ and the $\mathrm{CMC}$ can give useful information at the functional and at the component level during different stages of the product family design process.

\subsubsection{USEFULNESS OF THE OTHER COMMONALITY INDICES DURING STAGE 2}

The six component-based commonality indices described in Section 2.1 are also computed for the proposed design. A summary of the results is presented in Table 10.

While the $\mathrm{CI}^{(\mathrm{C})}$ and the DCI cannot be compared due to their moving boundaries, the remaining six indices
Table 9. CDI values for each function in the family.

\begin{tabular}{lc}
\hline Function & CDI \\
\hline Display information & 0.50 \\
Condition the image & 0.47 \\
Protect against the environment & 1.00 \\
View the scene & 0.40 \\
Light the scene & 1.00 \\
Control the exposure time & 0.92 \\
Store images & 1.00 \\
Advance film & 0.94 \\
\hline
\end{tabular}

Table 10. Commonality indices values for the single-use cameras.

\begin{tabular}{cccccccc}
\hline $\mathrm{PCl}$ & $\% \mathrm{C}$ & $\mathrm{TCCl}$ & $\mathrm{Cl}$ & $\mathrm{Cl}^{(\mathrm{C})}$ & $\mathrm{DCl}$ & $\mathrm{CDI}$ & $\mathrm{CMC}$ \\
\hline 54.00 & 44.84 & 46.50 & $56.80 \%$ & 2.81 & 1.86 & $78.00 \%$ & $61.00 \%$ \\
\hline
\end{tabular}

have fixed boundaries. By looking at these values, one can see that the CDI shows a higher value than the remaining indices that do not take component costs into consideration (i.e., $\mathrm{PCI}, \% \mathrm{C}$, TCCI, $\mathrm{CI}$ ). The reason is that the CDI focuses on how good a product family achieves variety, while keeping the non-differentiating components as common as possible. Except for the PCI, which does not consider the unique components in the analysis, the other indices will only reach their highest value when all the components, including the differentiating ones, are common between all the products. The PCI also achieves its highest value when the nonunique components are common and present in all products. By using the $\mathrm{CDI}$ and the $\mathrm{CMC}$, the value obtained is more realistic, as its higher boundary $(=1)$ can be achieved when all the non-differentiating components are made common between the products.

\section{Conclusions}

Commonality and diversity are the key to product family development: the idea is to have as much commonality as possible for the non-differentiating 
components, while maintaining sufficient variety for the differentiating components. To help resolve this tradeoff, the design for commonality and diversity method (DCDM) is proposed in this study based on two new commonality indices: the commonality diversity index (CDI) and the comprehensive metric for commonality (CMC). The DCDM helps designers manage the tradeoff between commonality and diversity during all the stages of the product family development. To demonstrate the method, an example application involving a family of single-use cameras is given. The DCDM has some limitations in that it does not help in generating or selecting product concepts; rather, it should be viewed as a tool to support the decisions made by designers.

Designing products and product families is a dynamic process, where the products can be modified throughout their life cycle to accommodate changes in customer needs, technology, markets, corporate strategies, competition, etc. Hence, it is very likely that the initial design of a product family will evolve to add, remove, or modify features, functions, components, etc. If changes are introduced, they can be immediately reflected in the $\mathrm{CDI}$ and $\mathrm{CMC}$ computation, and the $\mathrm{CDI}$ and $\mathrm{CMC}$ values enable to track the changes in requirements and where to focus to improve the design of the family. Future research suggests extending the
CDI and the CMC to include even more data and provide an even more comprehensive assessment of a product family during all the stages of product development. Another research direction is to incorporate concept generation and selection methods into the DCDM to make the whole process more repeatable and systematic. The assessment of the architecture design in the definition of the CDI and CMC may be included to see how these indices respond to different types of modular architecture types (bus, section, slot. etc.) $[37,38]$. Finally, the method may be expanded to include checkpoints all along the design process to help designers know when they reach a satisfactory balance of commonality and diversity in the product family being developed.

\section{Acknowledgments}

The support of the National Science Foundation under Career Grant No. DMI-0133923 and Grant Nos. IIS-0325321 and IIS-0325402 is gratefully acknowledged. Any opinions, findings, and conclusions or recommendations presented in this study are those of the authors and do not necessarily reflect the views of the National Science Foundation.
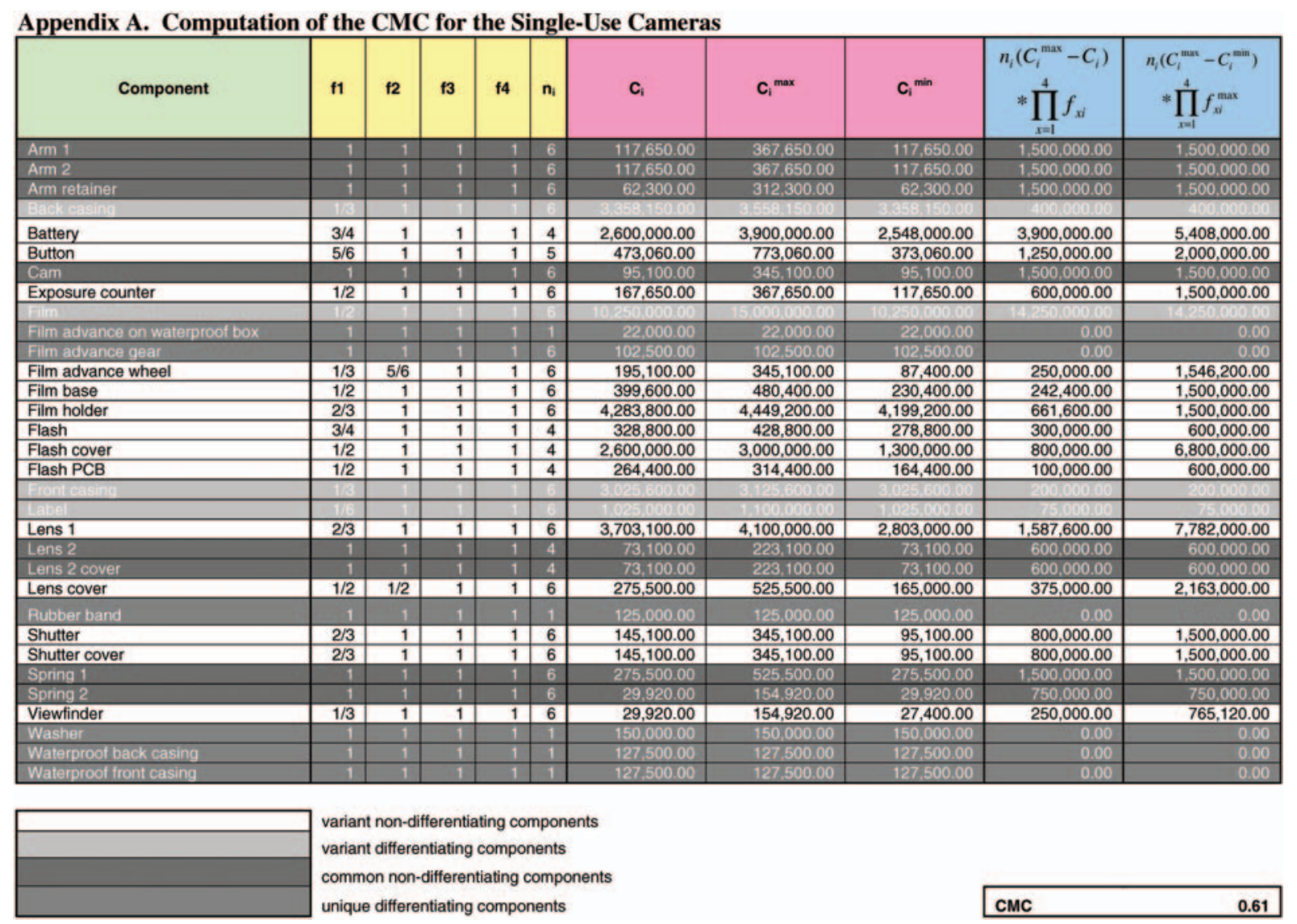

variant non-differentiating components variant differentiating components

common non-differentiating components

unique differentiating components 
Appendix B. Computation of the CDI for the Single-Use Cameras

\begin{tabular}{|c|c|c|c|c|c|}
\hline Function & Camera Components & $\begin{array}{l}\text { Exposure } \\
\text { Counter }\end{array}$ & Viewfinder & Fresh Cover & \\
\hline \multirow{7}{*}{$\begin{array}{c}\text { Display } \\
\text { Information }\end{array}$} & Diversity for the Function & $0 \%$ & $0 \%$ & $17 \%$ & \\
\hline & Plus digital & 1 & 1 & 2 & \\
\hline & High Definition & 2 & 2 & 1 & \\
\hline & Water \& Sport & 1 & 3 & - & \\
\hline & Power flash & 3 & 2 & 1 & \\
\hline & Black \& White & 1 & 1 & 2 & \\
\hline & Funsaver & 3 & 4 & 3 & \\
\hline Score & 0.53 & 0.60 & 0.40 & 0.59 & \\
\hline \multirow[t]{2}{*}{ Function } & & Lens 1 & Lens Cover & Film Base & \\
\hline & Diversity for the Function & $0 \%$ & $0 \%$ & $0 \%$ & \\
\hline \multirow{6}{*}{$\begin{array}{l}\text { Condition the } \\
\text { Image }\end{array}$} & $\begin{array}{l}\text { Plus digital } \\
\end{array}$ & 1 & 1 & 1 & \\
\hline & High Definition & 1 & 2 & 2 & \\
\hline & Water \& Sport & 1 & 1 & 1 & \\
\hline & Power flash & 2 & 3 & 3 & \\
\hline & Black \& White & 1 & 1 & 1 & \\
\hline & Funsaver & 3 & 4 & 4 & \\
\hline Score & 0.47 & 0.60 & 0.40 & 0.40 & \\
\hline \multirow[t]{2}{*}{ Function } & & ont Casing & Back Casing & $\begin{array}{l}\text { Waterproof } \\
\text { Front Casing }\end{array}$ & $\begin{array}{l}\text { Waterproof } \\
\text { Back Casing }\end{array}$ \\
\hline & Diversity for the Function & $100 \%$ & $100 \%$ & $100 \%$ & $100 \%$ \\
\hline \multirow{5}{*}{$\begin{array}{c}\text { Protect Against } \\
\text { the } \\
\text { Environment }\end{array}$} & Plus digital & $\begin{array}{l}1 \\
2\end{array}$ & 1 & & \\
\hline & High Definition & 2 & $\begin{array}{l}2 \\
3\end{array}$ & 1 & 1 \\
\hline & $\begin{array}{l}\text { Water \& Sport } \\
\text { Power flash }\end{array}$ & $\begin{array}{l}3 \\
4\end{array}$ & $\begin{array}{l}3 \\
2\end{array}$ & & \\
\hline & Black \& White & 1 & 1 & & \\
\hline & Funsaver & 5 & 4 & & \\
\hline Score & 1.00 & 1.00 & 1.00 & 1.00 & 1.00 \\
\hline \multirow[t]{2}{*}{ Function } & & Viewfinder & & & \\
\hline & Diversity for the Function & $0 \%$ & & & \\
\hline \multirow{6}{*}{ View the Scene } & Plus digital & 1 & & & \\
\hline & High Definition & 2 & & & \\
\hline & Water \& Sport & 3 & & & \\
\hline & $\begin{array}{l}\text { Power flash } \\
\text { Black \& White }\end{array}$ & $\begin{array}{l}2 \\
1\end{array}$ & & & \\
\hline & $\begin{array}{l}\text { Black \& White } \\
\text { Funsaver }\end{array}$ & 4 & & & \\
\hline & 0.40 & 0.40 & & & \\
\hline
\end{tabular}
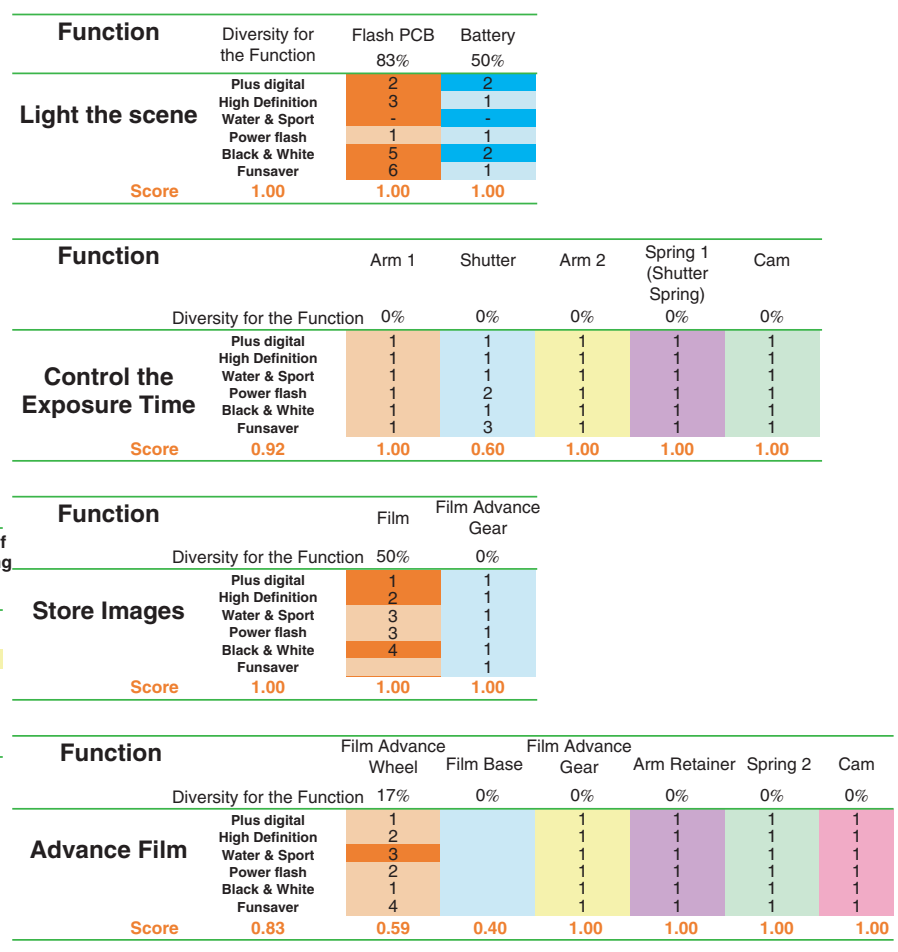

CDI Score for the Kodak family $\quad 0.77$

\section{References}

1. Collier, D.A. (1980). Justifying Component Part Standardization, In: Proceedings of Twelfth National AIDS Conference, Las Vegas, NV.

2. Collier, D.A. (1981). The Measurement and Operating Benefits of Component Part Commonality, Decision Sciences, 12(1): 85-96.

3. Collier, D.A. (1982). Aggregate Safety Stock Levels and Component Part Commonality, Management Science, 28(11): 1296-1303.

4. Collier, D.A. (1979). Planned Work Center Load in a Material Requirements Planning System, In: Proceedings of Eleventh National AIDS Meeting, New Orleans, LA.

5. Fisher, M., Ramdas, K. and Ulrich, K. (1999). Component Sharing in the Management of Product Variety: A Study of Automotive Braking Systems, Management Science, 45(3): 297-315.

6. Thonemann, U.W. and Brandeau, M.L. (2000). Optimal Commonality in Component Design, Operation Research, 48(1): 1-19.

7. Miller, S. (1999). VW Sows Confusion with Common Pattern for Models - Investors Worry Profits May Suffer as Lines Compete, Wall Street Journal: A.25.

8. Krishnan, V. and Gupta, S. (2001). Appropriateness and Impact of Platform-Based Product Development, Management Science, 47(1): 52-68.

9. Simpson, T.W., Seepersad, C.C. and Mistree, F. (2001). Balancing Commonality and Performance within the Concurrent Design of Multiple Products in a Product
Family, Concurrent Engineering: Research and Applications, 9(3): 177-190.

10. Thevenot, H.J. and Simpson, T.W. (2006). Commonality Indices for Product Family Design: A Detailed Comparison, Journal of Engineering Design, 17(2): 99-119.

11. Alizon, F., Shooter, S.B. and Simpson, T.W. (2006). Assessing and Improving Commonality and Diversity within a Product Family, In: Proceedings of ASME 2006 International Design Engineering Technical Conferences \& Computers and Information in Engineering Conference, Philadelphia, PA.

12. Thevenot, H.J. and Simpson, T.W. (2006). A Comprehensive Metric for Evaluating Component Commonality in a Product Family, In: Proceedings of ASME 2006 International Design Engineering Technical Conferences \& Computers and Information in Engineering Conference, Philadelphia, PA.

13. Meyer, M.H., Tertzakian, P. and Utterback, J.M. (1997). Metrics for Managing Research and Development in the Contact of the Product Family, Management Science, 43(1): 88-111.

14. Gershenson, J.K., Prasad, G.J. and Zhang, Y. (2003). Product Modularity: Definitions and Benefits, Journal of Engineering Design, 14(3): 295-313.

15. Gershenson, J.K., Prasad, G.J. and Zhang, Y. (2004). Product Modularity: Measures and Design Methods, Journal of Engineering Design, 15(1): 33-51.

16. Wacker, J.G. and Trelevan, M. (1986). Component Part Standardization: An Analysis of Commonality Sources and Indices, Journal of Operations Management, 6(2): 219-244. 
17. Martin, M.V. and Ishii, K. (1997). Design for Variety: Development of Complexity Indices and Design Charts, In: Proceedings of 1997 ASME Design Engineering Technical Conferences - Design for Manufacturability, Sacramento, CA.

18. Jiao, J. and Tseng, M.M. (2000). Understanding Product Family for Mass Customization by Developing Commonality Indices, Journal of Engineering Design, 11(3): 225-243.

19. Kota, S., Sethuraman, K. and Miller, R. (2000). A Metric for Evaluating Design Commonality in Product Families, Journal of Mechanical Design, 122(4): 403-410.

20. Siddique, Z., Rosen, D.W. and Wang, N. (1998). On the Applicability of Product Variety Design Concepts to Automotive Platform Commonality, In: Proceedings of ASME Design Engineering Technical Conferences - Design Theory and Methodology, Atlanta, GA.

21. Martin, M.V. and Ishii, K. (2002). Design for Variety: Developing Standardized and Modularized Product Platform Architectures, Research in Engineering Design, 13(4): 213-235.

22. McAdams, D.A., Stone, R.B. and Wood, K.L. (1999). Functional Interdependence and Product Similarity Based on Customer Needs, Research in Engineering Design, $111-119$

23. McAdams, D.A. and Wood, K.L. (2002). A Quantitative Similarity Metric for Design-by-Analogy, Journal of Mechanical Design, 124(2): 173-182.

24. Mattson, C.A. and Messac, A. (2005). Pareto Frontier Based Concept Selection Under Uncertainty, with Visualization, Optimization and Engineering - Special Issue on Multidisciplinary Design Optimization, 6(1): 85-115.

25. Nayak, R.U., Chen, W. and Simpson, T.W. (2002). A Variation-Based Method for Product Family Design, Engineering Optimization, 34(1): 65-81.

26. Simpson, T.W. (2004). Product Platform Design and Customization: Status and Promise, Artificial Intelligence for Engineering Design, Analysis and Manufacturing, 18(1): $3-20$.

27. Thevenot, H.J. and Simpson, T.W. (2005). Commonality Indices for Assessing Product Families, In: Product Platform and Product Family Design: Methods and Applications, pp. 107-129, New York City, NY: Springer.

28. Simpson, T.W., Maier, J.R.A. and Mistree, F. (2001). Product Platform Design: Method and Application, Research in Engineering Design, 13(1): 2-22.

29. Blecker, T., Abdelkafi, N., Kaluza, B. and Friedrich, G. (2006). Controlling Variety-Induced Complexity in Mass Customisation: A Key Metrics-Based Approach, International Journal of Mass Customization, 1(2/3): 272-298.

30. Shirley, G.V. (1990). Models for Managing the Redesign and Manufacture of Product Sets, Journal of Manufacturing and Operations Management, 385-404.

31. Page, A.L. and Rosenbaum, H.F. (1987). Redesigning Product Lines with Conjoint Analysis: How Sunbeam Does It, Journal of Production Innovation Management, 4(2): 120-137.

32. Siddique, Z. and Rosen, D.W. (2001). On Combinatorial Design Spaces for the Configuration Design of Product Families, Artificial Intelligence for Engineering Design, Analysis and Manufacturing: AIED AM, 15(2): 91-108.
33. Thevenot, H.J., Nanda, J. and Simpson, T.W. (2005). A Methodology to Support Product Family Redesign using Genetic Algorithm and Commonality Indices, In: Proceedings of 2005 International Design Engineering Technical Conferences \& Computers and Information in Engineering Conference, Long Beach, CA.

34. Labro, E. (2004). The Cost Effects of Component Commonality: A Literature Review Through a Management-Accounting Lens, Manufacturing \& Service Operations Management, 6(4): 358-367.

35. Simpson, T.W., Siddique, S. and Jiao, J. (2005). Product Platform and Product Family Design: Methods and Applications, New York: Springer.

36. Thevenot, H.J. (2006). A Method for Product Family Redesign Based on Component Commonality Analysis, Department of Industrial and Manufacturing Engineering, University Park, PA: The Pennsylvania State University.

37. Meyer, M.H. and X Lehnerd, J. (1997). The Power of Product Platforms: Building Value and Cost Leadership, New York: The Free Press.

38. Ulrich, K. (1995). The Role of Product Architecture in the Manufacturing Firm, Research Policy, 24(3): 419-440.

\section{Henri J. Thevenot}

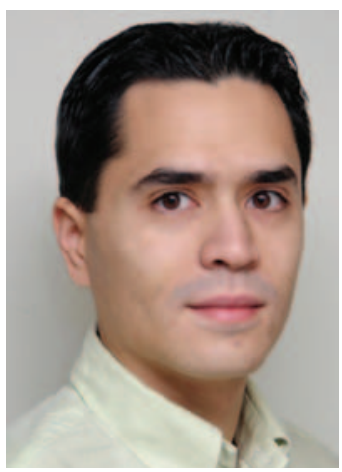

Dr. Henri J. Thevenot is a fixed-term instructor and a post-doctoral research associate working in product family design at Penn State University. He received a MS degree in Industrial Engineering from both Ecole Centrale de Lyon (France) and Penn State University in 2004, and $\mathrm{PhD}$ degree in Industrial Engineering from Penn State University in 2006 . He is currently developing optimization-based tools and methods for product family design and redesign in the context of globalization and innovation. He is also interested in developing tools to help designers in the early stage of the product design process.

\section{Fabrice Alizon}

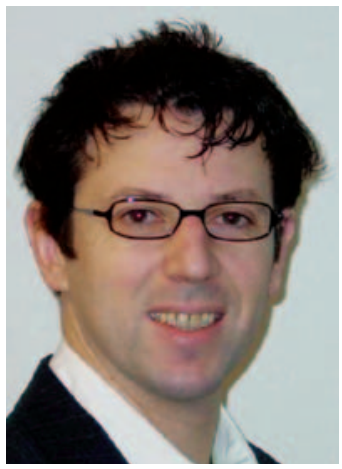

Dr. Fabrice Alizon is a research associate at the Pennsylvania State and Bucknell Universities. His research interests include product family specification, platform-based design, reuse design, and mass customization. He focuses his work on methods and methodologies to improve product family design. $\mathrm{He}$ is a SBDC 
consultant and works with several companies helping them to adopt a platform strategy. He received his MS and $\mathrm{PhD}$ degrees in Industrial Engineering from Ecole Centrale Paris (France). He also spent five years working at Renault carmaker, where he first worked on a virtual product/process design project before managing a digital validation team on vehicle project.

\section{Timothy W. Simpson}

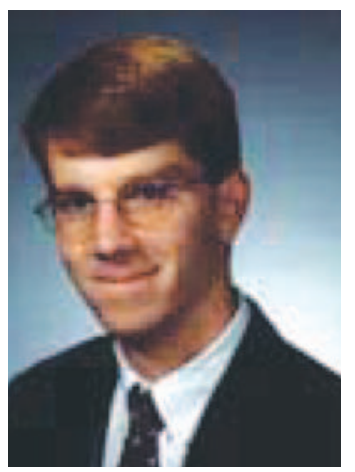

Dr. Timothy W. Simpson is a professor of Mechanical and Industrial Engineering and Engineering Design at the Pennsylvania State University. $\mathrm{He}$ received his $\mathrm{PhD}$ and MS degrees in Mechanical Engineering from Georgia Tech in 1998 and 1995, and his BS in Mechanical Engineering from Cornell University in 1994 . He is the Director of the Product Realization Minor at Penn State, and his research and teaching interests include product family and product platform design, product dissection and concurrent engineering, and visualization methods. $\mathrm{He}$ is a member of the ASME Design Automation Executive Committee and the AIAA Multidisciplinary Design Optimization Technical Committee.

\section{Steven B. Shooter}

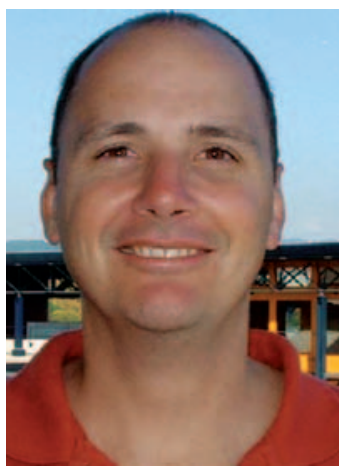

Dr. Steven B. Shooter is an associate professor of Mechanical Engineering at Bucknell University where he has taught since 1995. His research interests involve information management for design and the design of mechatronic systems and products. Integral to this research is the exploration of approaches for the capture, storage, and retrieval of product development information. $\mathrm{He}$ is a registered professional engineer in the state of Pennsylvania and has been the PI on numerous projects with industry involving new product development and the design of production infrastructure. He has been a researcher at NIST in the Design Engineering Technologies Group, a visiting professor at the Swiss Federal Institute of Technology in Lausanne (EPFL), and a process engineer for Sony Music Corporation. 